\title{
Música e infância no rádio: o programa Serelepe na Rádio UFMG - Educativa'
}

\author{
Eugênio Tadeu Pereira (UFMG, Belo Horizonte. MG) \\ etadeu@ufmg.br; serelepe@eba.ufmg.br
}

Cristiane da Silveira Lima (UFMG, Belo Horizonte. MG)

crislima1@yahoo.com.br

Gabriel Murilo Resende (UFMG, Belo Horizonte. MG)

gabriel.murilo@yahoo.com.br

Reginaldo Santos (UFMG, Belo Horizonte. MG)

regisnaldosantos@yahoo.com.br

Resumo: Este artigo tem como eixo temático a música infantil no rádio e faz uma reflexão a partir das experiências do programa Serelepe: uma pitada de música infantil, na Rádio UFMG Educativa, 104,5 FM, apresentado desde agosto de 2005 em Belo Horizonte. Seu caráter experimental é derivado da tentativa em integrar as áreas de teatro, música e comunicação, juntamente à proposta de difusão musical.

Palavras-chave: rádio, música infantil, criança, educação musical.

\section{Music and childhood on radio: the Serelepe program at UFMG - Educativa station}

Abstract: The main theme of this article is childhood music on the radio. It reflects about the experiences of Serelepe: uma pitada de música infantil (Serelepe: a pinch of kid's music), a program broadcasted at 104.5 FM of the UFMG Educativa Radio Station, since august 2005, in Belo Horizonte, Brazil. Its experimental outline is derived from an attempt to integrate the areas of Drama, Music and Communication, within the music broadcast proposal.

Keywords: radio, music for children, child, musical education.

\section{Apresentação}

O Serelepe: uma pitada de música infantil é um programa de rádio para crianças, oriundo do Curso de Graduação em Teatro da Escola de Belas Artes da UFMG, que vai ao ar todos os finais de semana ${ }^{2}$ pela Rádio UFMG Educativa 104,5 FM, na região metropolitana de Belo Horizonte, Minas Gerais. Ele pode ser ouvido também pela Internet, de qualquer lugar do mundo, no link www. ufmg.br/online/radio. Contatos com o programa podem ser feitos pelo e-mail serelepe@eba.ufmg.bre também pelo blog http://programaserelepe.blogspot.com.

0 programa é divido em quatro blocos: o Mão na Cumbuca - músicas daqui e acolá (dedicado exclusivamente a músicas brasileiras); o De Cabo a Rabo - quem conta um canto canta um conto (com histórias cantadas); o De Mala e Cuia - um passeio musical (com músicas de diferentes paises) e, por fim, o Balaio de Gato - de tudo um pouco (no qual tentamos misturar músicas, histórias, brincadeiras, dicas culturais, dentre outros).
Por estar inserido na programação de uma rádio educativa, o projeto tem se caracterizado por um processo contínuo de experimentação de diferentes linguagens, buscando integrar, principalmente, as áreas de Teatro, Música e Comunicação. Em 2007, ele se tornou também uma disciplina optativa no curso de Graduação em Teatro na EBA/UFMG, configurando um espaço de pesquisa para os alunos do curso que possibilita o improviso, a brincadeira, a atitude lúdica e, concomitantemente, uma visão crítica em relação à música, às formas de comunicação e às artes produzidas para crianças.

Ainda em 2007, os idealizadores do programa - e outros artistas - representaram o Brasil no $8^{\circ}$ Encontro da Canção Infantil Latino-americana e Caribenha, realizado na cidade de Valparaíso, no Chile ${ }^{3}$. Nesta ocasião, vários contatos foram estabelecidos com realizadores de programas radiofônicos para crianças em diferentes países da América Latina4. 
Sem a pretensão de tentar mudar o gosto dos ouvintes, nem de transformar a produção musical e cultural voltada para as crianças, o Serelepe tem buscado abordar o universo infantil sob um ponto de vista que tem a intenção de criar diferentes possibilidades de escuta e de tornar acessivel uma produção musical que julgamos de interesse para qualquer ouvinte, mas que não se encontra disponivel em outros canais de comunicação. Dessa forma, o Serelepe não se constitui em um programa alternativo, mas uma proposta alternativa de difusão musical. Objetivamos criar um espaço aberto para a divulgação de trabalhos feitos por, para e com crianças, buscando manter um determinado padrão de qualidade, valorizando a inventividade dos artistas e dos ouvintes. Nosso interesse está voltado para aguçar a sensibilidade auditiva e para incentivar a curiosidade musical, isto é, criar possibilidades e estímulos para uma escuta mais variada, rica e criativa, em que a imaginação do ouvinte possa "criar asas".

A programação do Serelepe privilegia artistas de todo o mundo com pouca inserção na grande mídia, mas também promovemos novas escutas de artistas já conhecidos. Determinadas músicas feitas para adultos, por exemplo, adotam uma linguagem que poderia ser igualmente apropriada por crianças, por causa de seu jogo de palavras, pelo modo como brincam e fazem humor. Um exemplo disso é a letra de As mariposa, de Adoniran Barbosa, cuja letra diz o seguinte:

As mariposa, quando chega o frio/ Fica dando vorta em vorta da lâmpida, pra se esquentar/ Elas roda, roda, roda e dispois se senta/ Em cima do prato da lâmpida pra discansar/ Eu sou a lâmpida e as muié é as mariposa/ Que fica dando vorta em vorta de $\mathrm{mim} /$ Toda as noite só pra me beijar.

Essa letra tem uma atmosfera que - a nosso ver - se relaciona com o universo infantil. 0 eu-lírico desses versos, com seu português "ruim", descreve como as mariposas ficam à sua volta, querendo lhe beijar. Mas não seria esta uma metáfora para falar do universo da sedução, da paquera? Também. Isso, entretanto, não exclui a apropriação lúdica que a imagem da lâmpada rodeada de mariposas permite.

Já o grupo Secos e Molhados, para citar outro exemplo, tem uma música bastante conhecida chamada O Vira, de João Ricardo e Luli, baseada nas histórias de lobisomem. Eis a letra:

O gato preto cruzou a estrada/ Passou por debaixo da escada/ E lá no fundo azul/ Da noite da floresta/ A lua iluminou/ A dança, a roda, a festa/ Vira, vira, vira, homem/ Vira, vira lobisomem.

Essa é uma releitura de uma lenda, associada muitas vezes ao universo infantil. Mas quem canta é Ney Matogrosso, ainda no grupo Secos e Molhados, com seu rosto pintado e suas coreografias ousadas. Tanto O Vira quanto As Mariposa são músicas que têm sido recebidas, com entusiasmo, pelas crianças. Mas por quê?
Revela-se a questão da especificidade do nosso público: o que e quem determina o que é música para criança? Criança gosta do quê? Como fazer uma programação musical dedicada ao público infantil que respeite a sua sensibilidade e a sua inteligência? É sobre essas indagações que este artigo reflete.

\section{2. "Pré-conceitos" e "pós-conceitos" sobre a relação música, infância e rádio: a ação do Serelepe}

Antes de pertencer a uma faixa etária, as crianças são seres humanos. A infância é uma fase da vida em que não apenas se assimilam informações e conteúdos, mas em que se aprendem hábitos e valores que podem ser levados por toda a vida. Erik Erikson (1976) nos instiga a pensar que a identidade do sujeito e de uma nação tem início nos rituais de infância. É durante a infância que os sujeitos mais desenvolvem suas habilidades básicas cognitivas e motoras necessárias à vida. É nesse periodo também que estruturamos a linguagem e compreendemos as "regras" que permitem a vida em comum. Por isso é tão importante o acesso à cultura, à educação e à saúde de qualidade, sobretudo nos primeiros anos. A formação que se tem na infância tem impactos diretos no futuro jovem/adulto.

Sendo assim, uma programação musical voltada para o público infantil deve estar atenta a este caráter de formação mais amplo - e não deve se voltar exclusivamente para "ensinar conteúdos ou boas maneiras" às crianças, tais como contar até dez, tomar banho ou escovar os dentes. Existem espaços mais apropriados e eficazes do que o rádio ou a música para esse tipo de orientação.

Observa-se que as crianças tendem a gostar das músicas às quais têm acesso pela sua família, pelos meios de comunicação (sobretudo a televisão) ou pelas influências de amigos. Muitas crianças só escutam aquilo que seus pais ou irmãos ouvem: uma música feita por e para adultos; na maioria das vezes, de fácil consumo.

No senso comum, o que define se uma música é ou não para crianças é um critério temático/ pedagógico. Acredita-se que música para crianças deve ser instrutiva (ensinando, por exemplo, a soletrar ou contar), deve ensinar hábitos de higiene pessoal e da boa educação (como escovar os dentes, tomar banho, dizer "por favor" e "obrigado", etc.), deve ensinar valores morais (como respeitar o próximo e cuidar da natureza). Outra característica encontrada nas letras das músicas para crianças é a frequência assombrosa de animais (e quase sempre mencionados no diminutivo), ou ainda, que versam sobre seres fantásticos, tais como monstros, bruxas ou bicho papão. Luis Maria Pescetti (in BRUM, 2005, p.31), discutindo a sua experiência em programas de rádio e com música para crianças, faz uma crítica irônica e bem-humorada, afirmando:

Nas canções infantis há mais animais do que na Arca de Noé. Estão cheias de bichos. Arainhas, galinhazinhas, cachorrinhos, mariposinhas, tartaruguinhas, gatinhos, lagartinhas, verminhos, 
vaquinhas, abelhinhas, pombinhos... Até vampiros. Basta! Por que ninguém fez uma canção infantil sobre um pocinho de petróleo, por exemplo? ${ }^{5}$.

Em seu texto, o autor apresenta também uma lista enorme de temas possiveis de serem abordados, que vão desde o liquidificador, o telefone, os pés das girafas, uma briga entre os pais, à perda de um avô, etc. 0 problema é menos o tema em si do que o modo como eles se tornaram exaustivos, padronizados e repetitivos, contribuindo muitas vezes para o estabelecimento de estereótipos e preconceitos. 0 universo infantil é frequentemente abordado de modo ingênuo e edulcorado, como se toda criança fosse alegre e feliz por natureza e em tempo integral, como se não vivesse também seus dilemas e conflitos... É uma espécie de infância idílica e inventada pelo adulto que não a viveu, pois ela nunca existiu e talvez, nunca existirá. Essa infância é cantada em verso e prosa como um mundo feliz idealizado. Mas quem de nós teve uma infância somente feliz?

Outras vezes, as crianças aparecem como seres barulhentos, inquietos e incapazes de ficarem em silêncio, que só sabem correr e fazer bagunça por todos os lados. São sempre ingênuos, pois vivem fazendo perguntas desconcertantes aos adultos, às quais só terão respostas quando atingirem uma suposta maturidade. No entanto, temas considerados sérios ou densos, tais como a perda, a morte, a dor, por exemplo, seriam mais apropriados para adultos.

Se, por um lado, esses temas mais comuns são um modus operandi no imaginário dos compositores de músicas para crianças; por outro lado há um leque de produções musicais que têm como mote temas diversos e que dizem claramente, e com poesia, sobre temas gerais da vida. Walter BENJAMIN (1924, p.237), já em 1924, ao falar sobre livros infantis, dizia que

a criança exige dos adultos explicações claras e inteligiveis, mas não explicações infantis, e muito menos as que os adultos concebem como tais. A criança aceita perfeitamente coisas sérias, mesmo as mais abstratas e pesadas, desde que sejam honestas e espontâneas.

Portanto, é de grande importância uma atitude sincera ao refletir acerca da ideia de infância que orienta as escoIhas em um programa infantil, seja do ponto de vista dos diálogos nas locuções, seja nas seleções musicais. Essa honestidade é decorrente de um respeito às crianças e aos demais ouvintes que procuramos ter.

Observa-se, também, uma falta de preocupação geral com a qualidade timbrística e com o nível de elaboração das produções musicais, quiçá artísticas de modo geral, voltadas para as crianças. A maior parte delas oferece pouca ou nenhuma inventividade e curiosidade que instiguem a imaginação do ouvinte: são frequentemente pouco elaboradas, baseadas em padrões rítmicos, melódicos e harmônicos bastante simplórios, com repetição exagerada de palavras no diminutivo, rimas fáceis e previsiveis, com uma instrumentação pobre e reduzida (normalmen- te composta por uma bateria eletrônica e um teclado), acompanhadas quase sempre por coreografias, como se criança não conseguisse ouvir música sem se mexer. Enfim, faltam variedade e riqueza nos arranjos sonoros e nos textos dessas músicas. 0 que se vê difundido nos grandes centros comerciais são coletâneas de canções de domínio público, reunindo pela enésima vez Ciranda cirandinha, Sapo Cururu e O Cravo brigou com a rosa. Não é o caso de desmerecer essas músicas, patrimônio cultural nacional, mas de convidar a trazer algo renovado ao rearranjá-las e regravá-las. A novidade objetivada não está meramente no aparato eletrônico ou na orquestra sinfônica. Acreditamos que essa novidade está em revelar, na própria música, aquilo que quase ninguém ouviu. Na própria música deve haver algo de novo, de frescor.

Os argumentos e justificativas que são dados para a recorrência desses padrões, normalmente, são a afirmação de que a mídia dá às crianças exatamente aquilo que elas querem. Ora, a relação dos meios de comunicação com a sociedade não pode ser vista de modo tão mecânico, reducionista e linear: os meios de comunicação não fornecem simplesmente os produtos desejados pelo público, nem Ihes impõem com facilidade, os seus produtos (como se o público não soubesse discernir e não tivesse autonomia alguma para refletir e escolher, entre os produtos oferecidos, aqueles que the mais interessam, como se consumisse tudo indiscriminadamente ${ }^{6}$ ). Afinal, o que constitui a comunicação é mais do que produzir e receber discursos. 0 que estabelece o vínculo comunicativo é "a ação de afetar e ser afetado pelo outro através de materiais significantes. É produzir/ consumir discursos, representações, sentidos para e em decorrência do outro - e sofrer, junto com ele (embora não necessariamente igual a ele), as consequências" (FRANÇA, 2006, p. 86). Entendemos os meios de comunicação como instrumentos sociais que dialogam permanentemente com os valores e com os sentidos compartilhados, reproduzindo-os e também os modificando. No entanto, também não podemos negligenciar o fato de que as pressões de natureza econômica influenciam sobremaneira no tipo de programação oferecido e que isso não implica necessariamente em uma preocupação com a qualidade ou com a riqueza dos produtos oferecidos. É notório que a mídia exerce uma grande influência no sentimento de massa, formando opinião, e operando no que GREEN $(1988 ; 1997)$ chama de significado musical delineado ${ }^{7}$.

No que diz respeito à produção dedicada às crianças, temos conhecimento de um conjunto substancial de artistas produzindo à margem dos grandes meios de comunicação e que, por isso, não alcançam um grande público. As músicas apresentadas por nós vêm de diversas partes do mundo. Muitos são os grupos espalhados pela América Latina. Citando alguns deles como: Los Musiqueros, Pro-Música do Rosário Niños, Mariana Baggio, Judith Akoschky e Luiz Pescetti, na Argentina; El Taller de los Juglares, na Venezuela; Julio Brum con los Pájaros Pintados, no Uruguai; Cantoalegre, Fundación Nueva Cultura e Coro Acuña, na Colômbia; Cântaro, Son de la Ciudad e 
Brenda Cervantes, no México. Em menor proporção, apresentamos algo do que é produzido na América do Norte (como Pete Seeger, dos Estados Unidos), na Europa (Les Petits Loups du Jazz, Bruno Coulais), na Ásia e na África (com músicas tradicionais encontradas nas pesquisas do canadense Francis Corpataux, etc).

No Brasil há uma variada produção musical contemporânea: Adriana Partimpim, Cecília Cavalieri França, Cuidado que Mancha, Curupaco, Duo Rodapião, Hélio Ziskind, Lydia Hortélio, Márcio Coelho e Ana Favaretto, Palavra Cantada, Teca de Brito, Viviane Beineke, dentre outros (sem mencionar os clássicos Arca de Noé, Saltimbancos, Adivinha o que é).

Ora, como as crianças poderiam gostar de tais artistas e de suas músicas se elas sequer os conhecem? É preciso haver espaços de visibilidade para outros tipos de produção musical para que as crianças possam escolher do que gostar, um espaço para ampliar as possibilidades que fazem parte da sua formação. De um modo geral, o universo radiofônico é fundado em uma música de consumo rápido, dirigido para uma comercialização imediata e de fácil substituição. Pouco ou nada é produzido no rádio para crianças em Belo Horizonte ${ }^{8}$. Já que o Serelepe não é regido por uma lógica mercadológica, ele não está preso a padrões dessa natureza.

É claro que o objetivo é também o de agradar - mas o gosto pode ser cultivado, criado, antecipado, descoberto, revisto. E ninguém gosta de uma coisa só: é possível gostar de coisas muito diferentes, sem que uma exclua a outra. Luis PESCETII (2005, p.29), escritor e músico, afirma ter sido várias vezes questionado sobre o fato de divulgar em seu programa músicas que não são originariamente voltadas para um público infantil, o que poderia aborrecer as crianças. Ele afirma, retrucando: "qual o perigo do aborrecimento? 0 zapping?"9 Se toda vez que a gente se aborrecesse com algo, a gente logo a abandonasse, não sairíamos do lugar. Ninguém abandona a leitura de um livro por não ter gostado de uma única página. Ele afirma, ainda, que essa pergunta sobre 0 aborrecimento é sempre feita por jornalistas, nunca pelos pais que escutam o programa com seus filhos $(2005$, p.30). $\mathrm{E}$, pelo que parece, nem pelas próprias crianças.

Nossa opinião está implícita naquilo que elegemos e inserimos em nossos programas para que os ouvintes possam ouvir, apreciar e escolher estar em sintonia com 0 programa ou buscar outra proposta. Portanto, o Serelepe almeja oferecer aos seus ouvintes o variado leque de possibilidades temáticas dedicadas à infância.

\section{A apreciação como pilar necessário ao desenvolvimento}

A música é uma linguagem de todos. Ela é um sistema simbólico que atravessa limites culturais. Somos responsáveis pela reprodução do que já foi e pela produção do que virá. Como construir uma cultura musical de amplo acesso, que não privilegie somente certos segmentos às vezes pueris dessa arte? SWANWICK (1979) acredita que a formação musical do ser humano desenvolve-se sobre três principais pilares: composição, apreciação e performance; e dois secundários: literatura e habilidades. Segundo FRANÇA (1998, p.68-69):

A apreciação, espera-se, permeia toda experiência musical, sendo um mediador básico para o desenvolvimento musical [...] $A$ escuta sensivel e atenta é determinante no fazer musical [...] Nestas circunstâncias, a apreciação estará monitorando a produção musical [...] ${ }^{10}$

A apreciação musical bem orientada desenvolve um senso crítico no ouvinte, permitindo-o julgar melhor o que ouve e o que se produz musicalmente. A programação do Serelepe busca oferecer oportunidades aos ouvintes de construírem referências de expressão musical de modo que, no futuro e no presente, possam fazer escolhas mais conscientes sobre o que ouvir. 0 problema não é uma escolha certa ou errada e sim a falta de opção ou a incapacidade de escolher com critérios mais amplos e relevantes. Reimer, citado por FRANÇA (1998, p.71), acredita que "escutar uma grande variedade de música funciona como um alicerce para decisões criativas" 11 e, segundo FRANÇA (1998, p.71), a apreciação musical "nutre o repertório de opções sobre o qual os estudantes agem criativamente, transformando, reconstruindo e reintegrando ideias em novas formas e significados." 12

A música é muito utilizada como plano de fundo para situações variadas. A proposta de escuta do Serelepe é trazê-la para o foco da atenção, instigando o ouvinte ao desafio de discernir as propostas composicionais: um instrumento diferente, o encadeamento dos sons, um tema de um personagem, sons estranhos, estórias "sem pé nem cabeça", etc.

Paynter, de acordo com FRANÇA (1998, p.70), argumenta que "a música não pode ser apreendida por contemplação passiva: é necessário comprometimento, escoIha, preferência e decisão." ${ }^{13} E$, para McAdams, segundo FRANÇA (1998, p.70), "a apreciação musical (bem como apreciar artes visuais ou ler um poema) é e deve ser considerada seriamente por um artista como um ato criativo por parte do participante". ${ }^{14}$

\section{Considerações sobre os nossos objetivos e a nossa experiência}

0 objetivo do Serelepe é fazer desse espaço aberto no rádio um lugar de escuta e de invenção. Temos o objetivo de experimentar outras linguagens, outros jeitos de fazer locução e de explorar as sonoridades, os textos e os $\mathrm{BGs}^{15}$, bem como divulgar trabalhos considerados pelos próprios integrantes coerentes e bem feitos, mas que não circulam na grande mídia - ou que até circulam, mas em outro contexto.

Além disso, o Serelepe tem sido um espaço de experimentação de diferentes propostas por parte de seus integrantes. 0 programa, na verdade, não conta com locutores profissionais e nem está dentro de convenções radiofônicas, como os das grandes rádios comerciais. É 
buscada, a cada programa, uma maneira diferente de nos comunicarmos com o ouvinte. Desde sua estreia até hoje, foram experimentadas diferentes formas de dizer o texto e quase foram criados personagens recorrentes (como o distraído que adora cantar e sempre perde o seu momento de falar ou a mal-humorada que às vezes é brava, outras vezes, romântica...). Os textos, escritos previamente, são elaborados de acordo com as músicas programadas, mas podem também não se referir exatamente a elas. Geralmente as locuções têm a função de ilustrar, comentar e inserir informações extras sobre as músicas e também de incluir comentários que vão além do que a música apresenta. Em outras palavras: não há um roteiro rígido, o que nos permite, a cada vez, reinventá-lo.

Quando a letra da música está em uma língua estrangeira, é de praxe descrever, em poucas palavras, o que ela diz. 0 repertório é escolhido a partir das discotecas dos próprios integrantes do projeto (que desenvolvem um intenso trabalho de pesquisa), das doações que o Serelepe recebe por intermédio da Rádio UFMG Educativa, pelo acervo da própria Rádio e de um acervo de mais de 200 CDs, disponibilizado pelo Duo Rodapião ${ }^{16}$, de Belo Horizonte - MG, que integra o Movimento da Canção Infantil Latino-Americana e do Caribe. Também informamos os dados sobre o intérprete, o compositor e o $C D$ de onde a música foi retirada. Outra característica do programa é a de tocar as músicas do princípio ao fim, ao contrário das práticas mais usuais do rádio que as cortam antes de seu término.

Algumas vezes, os locutores chamam a atenção para a letra, outras vezes para os instrumentos. Em nossas gravações, a brincadeira com texto está sempre presente, pois, como o brincar faz parte do universo da criança, os locutores usam esse meio como uma chave para entrar em contato com o universo infantil. Criamos diálogos fantasiosos entre nós mesmos, inventamos rimas sem pé nem cabeça, até arriscamos cantar de vez em quando, porém sempre valorizando uma escuta atenta às nuances de sentido, de ritmo, de sonoridades, respeitando a capacidade das crianças de compreenderem as brincadeiras propostas e fazerem, elas mesmas, as suas próprias associações. Queremos oferecer a elas alternativas, mas estabelecendo uma conversa, uma tentativa de aproximação. Tal como escreve o músico e professor uruguaio Julio Brum, o nosso trabalho (assim como o dele) é o de "viajar pela imaginação, de agitar a sensibilidade, de "fazer cosquinhas" nas ideias e valores que o sistema nos mostra como imutáveis e permanentes; trata-se de convidar a nossa infância a construir e explorar outros mundos" (BRUM 2005, p.67) ${ }^{17}$. Esse é o convite que o Serelepe faz aos ouvintes, ao temperar as suas manhãs de sábado com pitadas de música infantil, tentando "fazer cosquinhas" nas ideias mais usuais de música e de infância.

\section{Referências}

ANTUNES, Elton e VAZ, Paulo Bernardo Vaz. Mídia: um aro, um halo, um elo. In: GUIMARÃES, César e FRANÇA, Vera (orgs). Na mídia, na rua: narrativas do cotidiano. Belo Horizonte: Autêntica, 2006. pp.43-60.

BENJAMIN, Walter. Livros infantis antigos e esquecidos (1924). In: BENJAMIN, Walter. Obras escolhidas, vol.1. Magia e técnica, arte e política. São Paulo: Brasiliense, 1985. pp.235-243.

BRUM, Julio (Org). Panorama del Movimiento de la Canción Infantil Latinoamericana y Caribeña: Estúdios, reflexiones y propuestas acerca de las canciones para la infancia. Montividéo: Papagayo Azul, 2005.

ERIKSON, Erik. Identidade - juventude e crise. Rio de Janeiro: Zahar, 1976.

FRANÇA, Maria Cecilia Cavalieri; SWANWICK, Keith. Composing, performing and audience-listening as symmetrical indicators of musical understanding. University of London, 1998 297f. enc. Tese (doutorado).

FRANÇA, Vera. Sujeitos da comunicação, sujeitos em comunicação. In. GUIMARÃES, César e FRANÇA, Vera (orgs). Na mídia, na rua: narrativas do cotidiano. Belo Horizonte: Autêntica, 2006. pp.61-88.

GREEN, Lucy. Pesquisa em Sociologia da Educação Musical. Revista da ABEM, Salvador, ano 4, n. 4, p. 25-35, set. 1997. Trad. Oscar Dourado.

MACHADO, Arlindo. Máquina e imaginário - o desafio das poéticas tecnológicas. 3. ed. São Paulo: EDUSP, 2001.

SWANICK, Keith A Basis for Music Education, London: Routledge, 1979. 


\section{Leitura recomendada:}

BENJAMIN, Walter. História cultural do brinquedo (1928). In: BENJAMIN, Walter. Obras escolhidas, vol.1. Magia e técnica, arte e política. São Paulo: Brasiliense, 1985. pp.244-248.

Brinquedo e brincadeira - observações sobre uma obra monumental (1928). In: BENJAMIN, Walter. Obras escoIhidas, vol.1. Magia e técnica, arte e política. São Paulo: Brasiliense, 1985. pp.249-253.

GREEN, Lucy. Music on Deaf Ears: Musical meaning, ideology and education. Manchester and New York: Manchester University Press, 1988.

Music, Gender, Education. Cambridge: Cambridge University Press, 1997.

McADAMS, Stephen 'The auditory image: a metaphor for musical and psychological research on auditory organization'. In: CROZIER, W. R. and CHAPMAN, A. J. (eds) Cognitive Processes in the perception of Art, Amsterdam: Elsevier, 1984.

NACHMANOVITCH, Stephen. Ser Criativo - o poder da improvisação na vida e na arte. São Paulo: Summus, 1993.

PAYNTER, John. Music in the Secondary School Curriculum. Cambridge: Cambridge University Press, 1982.

PEREIRA, Eugenio Tadeu. A difusão da canção infantil. In: Anais do $4^{\circ}$ Encontro da Canção Infantil Latino-americana e Caribenha. Córdoba, Argentina: Fundação Takian Cay, 1999.

. Brincar, brinquedo, brincadeira, jogos, lúdico: convergências e divergências. Revista Presença Pedagógica. v.7, n.38. Mar.-Abr./2001.

. Brinquedos e infância. Revista Presença Pedagógica. v.8, n.44, Mar.-Abr./2002. Ed. Dimensão. Publicado também em: Revista Criança. n.37. Nov./2002. Ministério da Educação.

REIMER, Bennett. A Philosophy of Music Education, New Jersey: Prentice Hall, 1970/1989.

SCHAFER, Murray. Ouvido Pensante. São Paulo: Unesp, 1991.

\section{Notas}

1 Uma versão preliminar deste texto foi publicada na Presente! Revista de Educação, ano 17 n. 65, Salvador, Ago/Nov/ 2009. Para a Revista PerMusi vários pontos foram acrescidos e revisados.

2 A partir de 08 de marco de 2008, o programa passou a ser apresentado aos sábados as 9h da manhã, tendo uma hora de duração. 0s programas "pilulas", que duravam de 5 a 8 minutos e que eram apresentados diariamente às 9 h45min, desde 07 de setembro de 2005 . Atualmente o programa está sendo exibido em partes aos domingos às 9 horas da manhã, conjuntamente a outros programas para crianças. 0 Serelepe começou suas atividades a partir de um convite do coordenador da rádio, prof. Elias Santos e por Rosaly Senra, no mesmo ano de inauguração da UFMG Educativa.

$309^{\circ}$ Encontro da Canção Infantil Latino-americana e Caribenha ocorreu entre 19 e 25 de outubro de 2009, no México. Outras informações no site: http://9cancioninfantil.cnart.mx/. Último acesso em: 22/10/2009. Em 2011 o Brasil sediará o 10 Encontro, sob a coordenação de Márcio Coelho e Ana Favaretto.

4 São eles: ARGENTINA: programa Taracatá, coordenado por Julio Calvo (www.radiodelaciudad.gov.ar), que, lamentavelmente, não está mais no ar; Me extraña araña, na AM 750 - Radio Nacional Córdoba, sob coordenação de Coqui Dutto; Radio Mafalda, produzida por Alejo e Julio Villarroel (http://radiomafalda.dynalias.net:86); Vampiro Negro, da Radio Nacional Argentina 870 AM, produzido por Luís Pescetti. URUGUAI: Para Escucharte mejor, da Emisora del sur, sob coordenação de Suzana Bosch (www.sodre.gub.uy). MÉXICO: ¡Ay escuintles! (www.radioeducacion.edu.gob.mx), programa de curta duração produzido por Gabriel Sanvincente; Hola Luis, da Radio Universidad Nacional Autónoma de México 96.1 FM, também produzido por Luis Pescetti. PORTO RICO: Ambos a Dos, cuentos y canciones produzido por Nelie Lebrón (www.radiouniversidad.pr).

5 Tradução nossa, a partir do original: "en las canciones infantiles hay más animales que en el Arca de Noé. Están llenas de bichos. Añaritas, gallinitas, perritos, maripositas, tortuguitas, gatitos, gusanitos, vaquitas, abejitas, palomitas... hasta vampiros. !Basta! ¿Por qué nadie hizo una canción infantil a un pocito de petróleo, por ejemplo?"

$6 \mathrm{Na}$ tradição dos estudos em comunicação, existem diferentes abordagens da relação entre a mídia e a sociedade. Algumas dessas tradições de pesquisa hoje são muito criticadas pelo seu mecanicismo e linearidade como, por exemplo, a Escola Funcionalista Americana, também conhecida pela rubrica da Mass Communication Research, que pautava seus estudos a partir da ótica dos efeitos dos meios de comunicação sobre o público, e a Escola de Frankfurt, ou "Teoria Crítica", que desenvolveu toda uma abordagem acerca da Indústria Cultural, mas enfatizando o caráter ideológico dos meios de comunicação. Ambas se sustentam no paradigma informacional, que aborda as instâncias de produção de mensagens e de recepção como pólos isolados e separados, cabendo à produção um papel ativo e de controle sobre as mensagens, ao passo que o receptor é relegado ao lugar de um consumidor passivo. Esse paradigma já não é consensual e uma nova perspectiva vem sendo desenvolvida, apoiando-se no chamado paradigma relacional ou praxiológico. Para um breve panorama dessas teorias, cf. FRANÇA, Vera. Sujeitos da comunicação, sujeitos em comunicação. In. GUIMARÃES, César e FRANÇA, Vera (orgs). Na mídia, na rua: narrativas do cotidiano. Belo Horizonte: Autêntica, 2006. pp.61-88. Para uma reflexão acerca da mídia, compreendida não apenas em sua dimensão de aparato técnico, mas também em seu caráter relacional, que permite uma modalidade de experiência assentada no transporte e deslocamento de signos, cf. ANTUNES, Elton e VAZ, Paulo Bernardo Vaz. Mídia: um aro, um halo, um elo. In: In. GUIMARÃES, César e FRANÇA, Vera (orgs). Na mídia, na rua: narrativas do cotidiano. Belo Horizonte: Autêntica, 2006. pp.43-60.

7 Lucy Green considera como significado musical inerente as relações dos materiais sonoros entre si em uma peça musical, ou entre as demais estruturas musicais de uma cultura; e significado musical delineado como a relação inseparável, consciente ou não, dos significados inerentes com seu contexto social de produção, distribuição e recepção (GREEN, 1997b, p.27-29).

8 Uma das poucas referências que conhecemos foi o programa Carretel de Invenções, idealizado pro Francisco Marques, o Chico dos Bonecos e produzido pela AMEPPE - Associação Movimento de Educação Popular Integral Paulo Englert e pela Fundação Fé e Alegria, que foi ao ar durante alguns anos pela Rádio Favela e outras rádios comunitárias, no início da década de 1990. Esse programa ainda é ouvido em algumas rádios brasileiras. Mas vale lembrar: a concessão da Rádio Favela também é de rádio educativa. Entre as rádios comerciais, desconhecemos outros programas.

9 Zapping: estratégia de mudar de canal possibilitada, sobretudo, pelo advento do controle remoto e que instaura uma nova modalidade de recepção, no qual o espectador/ ouvinte não se fixa em um único programa, mas ao contrário, se desloca de um a outro livremente. "0 zapping é mania que 
tem o espectador de mudar de canal a qualquer pretexto, na menor queda de ritmo ou de interesse do programa e, sobretudo, quando entram os comerciais". (MACHAD0, 2001, p. 143).

10 Tradução nossa, a partir do original: Listening is expected to pervade any active musical experience, being a basic medium for musical growth. [...] Sensitive and discerning listening is determinant in musical making. [...] In these circumstances, listening will be monitoring the musical output [...].

11 Tradução nossa, a partir do original: Reimer believes that 'listening to a great variety of music' works as "fodder for creative decisions"

12 Tradução nossa, a partir do original: It nourishes student's repertoire of options upon which to act creatively, transforming, reconstructing and reintegrating ideas into new shapes and meanings.

13 Tradução nossa, a partir do original: Paynter argues, music cannot "be apprehended by passive contemplation: it calls for commitment; for choice, preference, and decision."

14 Tradução nossa, a partir do original: Musical listening (as well as viewing visual arts or reading a poem) is and must be considered seriously by an artist as a creative act on the part of the participant.

15 BG é a abreviação do termo técnico background, usado para designar os sons ou músicas que estão de fundo, em segundo plano, acompanhando a locução.

16 Duo formado por Miguel Queiroz e Eugênio Tadeu que, desde 1994, produz espetáculos e CDs dedicados ao público infantil.

17 Viajar por la imaginación, de agitar la sensibilidad, de "hacerle cosquillas" a las ideas y valores que el sistema nos muestra como inmutables y permanente, se trata de invitar a nuestra infancia a construir y explorar otros mundos.

Eugênio Tadeu Pereira é Professor do Curso de Graduação em Teatro da Escola de Belas Artes da UFMG. Mestre em Educação - FaE/UFMG, Doutorando em Artes Cênicas - ECA/USP; integrante do Duo Rodapião; idealizador e coordenador do projeto Pandalelê - Laboratório de Brincadeiras - CP/UFMG (1993 a 2003) e integrante do Movimento da Canção Infantil Latino-Americana e do Caribe.

Cristiane Lima é Mestre em Comunicação Social - FAFICH/UFMG, bacharel em Radialismo pela UFMG, professora de Música no Centro Pedagógico da Escola de Educação Básica e Profissional da UFMG e na Fundação de Educação Artística.

Gabriel Murilo Resende é Licenciado em Música pela UFMG, professor de música na Pró-Music e no Centro de Musicalização Infantil da Escola de Música da UFMG, compositor, arranjador e produtor musical.

Reginaldo Santos é Licenciado em Teatro pelo curso de Graduação da Escola de Belas Artes da UFMG, Professor de Teatro do Galpão Cine Horto, onde também atua no projeto Conexão Galpão. Coordenador Artístico do Centro de Referência de Cultura e Desenvolvimento Social de Matozinhos. 